\title{
ON SENSITIVITY OF QUASILINEAR ELLIPTIC BOUNDARY VALUE PROBLEMS USING FRIEDRICHS CONSTANT
}

\author{
KARL DVORSKY AND JOACHIM GWINNER
}

\begin{abstract}
We treat nonresonance of quasilinear elliptic equations with nonlinear boundary conditions via Friedrichs constant $c_{\star}$. Here we give a sensitivity result for nonlinear perturbations of the right hand side and provide an explicit estimate for $c_{\star}$ in convex domains. Finally, to illustrate our results we discuss the $p$-Laplacian case.
\end{abstract}

Mathematics subject classification (2010): 35J62, 35B20.

Keywords and phrases: quasilinear elliptic equation, perturbations, Friedrichs inequality.

\section{REFERENCES}

[1] P. Amster, M. C. Mariani and O. Méndez, Nonlinear boundary conditions for elliptic equations, Electron. J. Differ. Equ., 2005, 144 (2005), 1-8.

[2] N. ANANE AND N. TsOULI, On a nonresonace condition between the first and the second eigenvalues for the p-Laplacian, International Journal of Mathematics and Mathematical Sciences, 26, (2001), $625-634$.

[3] M. Cuesta, J.-P. Gossez And P. OMARI, Nonresonance to the right of the first eigenvalue for the one-dimensional p-Laplacian, Nonlin. Anal., 38 (1999), 481-496, doi:10.1016/S0362546X(98)00210-7.

[4] E. Di Benedetto, Degenerate Parabolic Equations, Springer, New York, 1993.

[5] P. DRÁBEK AND S. B. ROBINSON, Resonance problems for the $p$-Laplacian, Journal of Functional Analysis, 169 (1999), 189-200, doi:10.1006/jfan.1999.3501.

[6] K. Dvorsky, J. Gwinner And H.-D. Liess, A fixed point approach to stationary heat transfer in electric cables, Mathematical Modelling and Analysis, 16, 2 (2011), 286-303, doi:10.3846/13926292.2011.580436.

[7] K. DVORSKY, Analysis of a nonlinear boundary value problem with application to heat transfer in electric cables, Ph.D. Thesis, Univ. German Federal Armed Forces, Munich, 2012.

[8] A. El Hachimi And J.-P. Gossez, A note on a nonresonance condition for a quasilinear elliptic problem, Nonlin. Anal., 22 (1994), 229-236, doi:10.1016/0362-546X(94)90037-X.

[9] L. GASINSKI, Strongly resonant quasilinear elliptic equations, Nonlin. Anal., 68 (2008), 969-980, doi:10.1016/j.na.2006.11.053.

[10] D. G. De Figueiredo AND J.-P. Gossez, Nonresonance below the first eigenvalue for a semilinear elliptic problem, Math. Ann., 281 (1988), 589-610, doi:10.1007/BF01456841.

[11] J. V. A. GoncAlves, On nonresonant sublinear elliptic problems Nonlin. Anal., 15 (1990), 915-920, doi:10.1016/0362-546X(90)90074-Q.

[12] E. M. LANDESMAN AND A. C. LAZER, Nonlinear perturbations of linear elliptic boundary value problems at resonance, J. Math. Mech., 19 (1970), 609-623.

[13] S. MARTÍNEZ AND J. D. Rossi Weak solutions for the p-Laplacian with a nonlinear boundary condition at resonance, Electron. J. Differ. Equ., 2003, 27 (2003), 1-14.

[14] J. MAWHIN AND J. R. WARD, Nonresonance and existence for nonlinear elliptic boundary value problems, Nonlin. Anal., 6 (1981), 677-684, doi:10.1016/0362-546X(81)90084-5.

[15] J. MAWhin, J. R. WARD AND M. WILlEM, Variational methods and semi-linear elliptic equations, Arch. Rational Mech. Anal., 95, 3 (1983), 269-277. 
[16] S. G. Mikhlin, Equivalent norms in Sobolev spaces and norms of extension operators, Sibirskii Matematicheskii Zhurnal, 19 (1977), 1141-1153.

[17] P. OMARI AND F. ZANOLIN, Resonance at two consecutive eigenvalues for semilinear elliptic equations, Ann. Mat., 163 (1993), 181-198, doi:10.1007/BF01759021.

[18] L. E. Payne And H. F. Weinberger, An optimal Poincaré inequality for convex domains, Arch. Rational Mech. Anal., 5 (1960), 286-292, doi:10.1007/BF00252910.

[19] S. SONG AND C. TANG, Resonance problems for the p-Laplacian with a nonlinear boundary condition, Nonlin. Anal., 64 (2006), 2007-2021, doi:10.1016/j.na.2005.07.035.

[20] E. ZEIDLER, Nonlinear Functional Analysis and its Applications, II/B, Springer, New York, 1990. 